\title{
INNOVATION CAPACITY AND POTENTIAL IN INDONESIAN MANUFACTURING SECTOR
}

\author{
Novi Maryaningsih \\ Department of Economic and Monetary Policy \\ Bank Indonesia \\ Jakarta, Indonesia \\ E-mail: nmaryaningsih@bi.go.id \\ Oki Hermansyah \\ Department of Economic and Monetary Policy \\ Bank Indonesia \\ Jakarta, Indonesia \\ E-mail: oki_hermansyah@bi.go.id
}

\begin{abstract}
Manufacturing sector with comparative advantage, product diversification, and integration to global supply chain network will support sustainability of domestic economy. Manufacturing sector is the fourth largest in labor absorption as it constitutes $26.8 \%$ of total GDP (average 2005-2010). Nevertheless, its growth deteriorates, from $9.2 \%$ yoy (1991-1996) to $4.0 \%$ yoy (2005-2010).

The decrease indicates some problems in labor productivity and competitiveness of domestic firms in manufacturing sector, which are lack of productivity and technological progress in manufacturing sector respectively. Both aspects are mainly determined by presence of high-skilled labor and $R \& D$ activity.

Based on the background, this study is to reveal the innovation capacity and potential development in manufacturing sector based on Large and Medium Enterprise Statistic survey of Statistics Indonesia (BPS). To obtain weights of determinant factors of innovation capacity and potential, we used Analytic Network Process (ANP) method to gauge innovation level of each firm in manufacturing sector.

This study found that most of Indonesian manufacturing firms have a low R\&D activity. About 74\% (16.851 firms) categorized as low innovation, whilst 5\% (1.152 firms) considered as high innovation. These facts themselves reflect the capability of firms to compete in the global market through exports. Of low level firms, merely $15 \%$ (2.516 of 16.851 firms) is involved in export activity. On the contrary, 49\% (561 of 1.152 firms) of high innovation level is involved in export activity, mainly in food, chemical, furniture, and textile sectors. By spatial, highly innovative firms which doing exports mainly located in Java. It is possibly due to a high quality of infrastructure and human capital support which is relatively better in Java than any other parts in Indonesia.
\end{abstract}

Keywords: innovation, manufacturing sector, ANP, network, human capital. 


\section{Introduction}

Manufacturing sector is an important sector for Indonesian economy, in terms of its contribution to Growth Domestic Product (GDP) and labor absorption. The manufacturing sector is the largest sector that contributes $26.8 \%$ of GDP and absorbs $12 \%$ of the total labor. However, the performance of the manufacturing sector experienced a gradual decline from $9.2 \%$ yoy (1991-1996) to $4.0 \%$ yoy (2005-2010). The deterioration of the manufacturing sector indicates that some problems still emerge. Important issues are related to the development of labor productivity in the manufacturing sector which tends to slow down in recent years. Also the low competitiveness of domestic manufacturing firms as indicated by the slowdown of its export performance.

The main cause of the weakening of productivity in the manufacturing sector is related to the weakening of total factor productivity (TFP) growth. Conceptually, low TFP growth reflects low support of innovation capacity and technological progress. Both aspects are extremely determined by the availability of qualified human resources, and R\&D.

In economic growth theory, innovation economy describes the development of manufacturing activities that have a high innovation capacity so it becomes the engine of growth. Based on the concept, capability of a country to develop human capital and innovation capacity of manufacturing sector will have an impact on attaining high and sustainable economic growth, which in turn increases the economic welfare. As one of the main sectors that support growth, the presence of innovation capacity and potential in the manufacturing sector, particularly in large and medium enterprises, is a key to sustainable economic growth. Based on the background, this study aims to determine the extent of the development of innovation capacity and potential in manufacturing sector.

\section{Literature Review}

Schumpeter (1942) stated that innovation acts as a catalyst for growth. Innovation can be defined as the application of new ideas to the products and processes of a firm's activities. Freeman et al. (1988) sees this as a process that includes the technical, design, manufacturing, management, and commercial activities involved in the marketing of a new or improved product or the first use of a new or improved manufacturing process or equipment. Roberts (1988) stated that the overall management of technological innovation includes the organization and direction of human and capital resources towards effectively: (1) creating new knowledge, (2) generating ideas aimed at new and enhanced products, manufacturing processes and services, (3) developing those ideas into working prototypes and (4) transferring them into manufacturing distribution and use.

Therefore, the innovation has the potential to greatly increase the performance of the firms. Firms must be innovative to survive and prosper in a competitive economy (Feeny and Rogers, 2001). Along with technological progress, innovation capacity plays a role in increasing the total factor productivity (TFP) which is able to boost the overall economy and encouraging competitiveness to a higher level. Both aspects are largely determined by the availability of qualified human resources (human capital) and R\&D activities.

From our observation, the importance of innovation in manufacturing sector has not been explored yet in Indonesia. There have been no empirical studies that specifically tried to 
identify the factors that are believed to be the determinant of the innovation capacity and potential in the manufacturing sector in Indonesia. Moreover, the fact that Indonesia is experiencing decreased growth, share to GDP, and labor absorption in manufacturing sector strengthen our motivation to identify the cause from the innovation perspective.

\section{Hypotheses/Objectives}

This study aims to identify the factors that influence manufacturing sector to improve its innovation capacity. More specific, this study is trying to measure the weight of innovation factors in BPS survey, and to map manufacturing sector based on the weight. The results of this study are expected to provide input for the development of innovation capacity held by the government.

\section{Research Design/Methodology}

The data is obtained from Large and Medium Enterprise Statistic survey (SIBS) of Statistics Indonesia (BPS) which covers 29,469 firms. The survey covers R\&D activities related to the development of human resources and technology. By this survey, we try to identify which factor is the most important in developing innovation. Innovation capacity and potential are measured by capital, both physical and human; and R\&D activities and the adequacy of skilled labor that support the innovation activities as shown on table below.

\begin{tabular}{|c|c|c|}
\hline & Innovation Factor & Proximity \\
\hline \multirow[t]{3}{*}{1} & \multirow{3}{*}{$\begin{array}{l}\text { Capital } \\
\text { (Innovation Capacity) }\end{array}$} & 1) Computer use \\
\hline & & 2) Spending to enhance human resources quality \\
\hline & & 3)Number of labor with minimum bachelor degree \\
\hline \multirow[t]{3}{*}{2} & \multirow{3}{*}{$\begin{array}{l}\text { Training Activity } \\
\text { (Innovation Potential) }\end{array}$} & 1) Firm as a trainer \\
\hline & & 2) Training for labor \\
\hline & & 3) Type of training for labor \\
\hline \multirow[t]{3}{*}{3} & \multirow{3}{*}{$\begin{array}{l}\text { Innovation Activity and } \\
\text { R\&D } \\
\text { (Innovation Potential) }\end{array}$} & 1) Product/process innovation activity \\
\hline & & 2) Spending for R\&D \\
\hline & & 3) Labor in R\&D unit \\
\hline
\end{tabular}

The cluster are constructed based on pillar of infrastructure in The Global Competitiveness Report 2010-2011, among others are computer use pillar, high education and training pillar, and innovation capacity pillar.

To help measuring the weight of each factor, we construct a questionaire based on model which consists of clusters and nodes. We design a comparison between clusters and nodes and then compile the result as matrices. The questionaire itself are distributed to manufacturing sector experts. We then aggregate all the matrix results by simple average and analyse it to find inconsistency may exist. If there's any inconsistency, we will take a few judgments, based on consistency index rule Consistency Index $(\mathrm{CI})=\frac{\lambda_{\max }-n}{n-1}$. 


\section{Data/Model Analysis}

Based on the research design, we use the general network below:

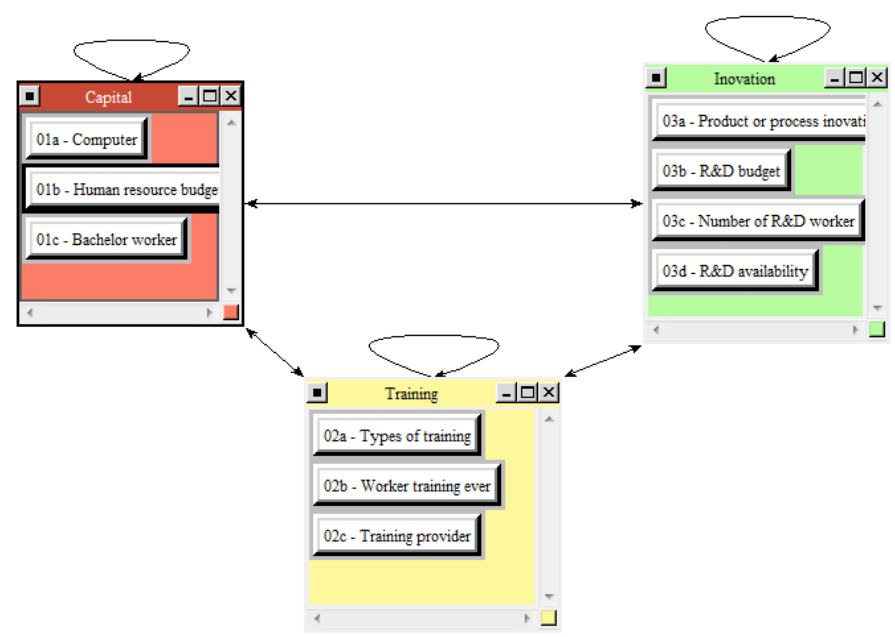

To measure the weight of each node, we generate a questionaire (see appendix for illustration), based on the design above, in order to make comparison matrices. From the consistency index formula, we find some inconsistency. After a few judgments yet still maintaining general preference of respondents, we obtain a matrix of consistency index as shown on table below.

Based on this judgment, we finally obtain a priority matrix as shown on appendix.

\section{Limitations}

Although this research found an interesting result on manufacturing sector characteristic, it was supported by the small-covered questionaire due to time limitation. In the near future, the survey will be broaden to a larger scale in order to obtain a more robust results. From the data perspective, the SIBS 2006 data still contains some weaknesses, especially related to the consistency between the raw data to the definitions contained in the questionnaire. As an illustration, for a firm as a trainer category, for example, of a 29,469 firms surveyed, only 22,757 firms responded. Of these, only as many as 6,485 companies $(22 \%)$ who responded in accordance with the choice of answers provided by the BPS. Therefore, the results obtained do not necessarily depict the actual conditions in the manufacturing sector. In other categories, such as the number of workers at the R\&D, regardless of the number of its workforce, the firm will be weighted. So, the weight does not reflect the ideal amount of human resources required by the firm. 


\section{Conclusions}

Based on priority matrix, product/process innovation (36\%) is identified as the most important factor for the development of innovation in Indonesian manufacturing sector, followed by the availability of the budget to support the R\&D activity by $26 \%$. In terms of training, the firms' role in training their employees based on their interests and competence have the biggest role in supporting innovation activities of firms (10\%). In terms of capital, although the bachelor labor only support innovation activities $3 \%$, it is only about labor not be placed in the R\&D unit. It becomes different when labor factor is placed in the unit R\&D so they contribute to the development of the innovation by $17 \%$.

Based on these weights, we can find that in general, most of firms in the manufacturing sector still have a low R\&D activity. About $74 \%$ of the firms' have low innovation capacity and potential, while $21 \%$ of companies are innovating, and only $5 \%$ of companies have a high innovation capacity and potential.

These facts reflect the capability of firms to compete in the global market through exports. Of low level firms, merely $15 \%$ (2.516 of 16.851 firms) is involved in export activity. On the contrary, 49\% (561 of 1.152 firms) of high innovation level is involved in export activity, mainly in food, chemical, furniture, and textile sectors. By spatial, highly innovative firms which doing exports mainly located in Java. It is possibly due to a high quality of infrastructure and human capital support which is relatively better in Java than any other parts in Indonesia. From these findings, ANP helps to map the current and clarify the decline in Indonesian manufacturing sector.

\section{Key References}

Feeny S. and M. Rogers, 2001. Innovation and Performance: Benchmarking Australian Firms", Working Paper No. 7/01, Melbourne Institute.

Freeman, C. and P. Carloza, 1988. The Structural Crisis of Adjustment, in G. Dosi, C. Freeman, R. Nelson, G. Silverberg dan L. Soete, (eds.), Technical Change and Economic Theory. Pinter Publishers, London.

Saaty, T.L.. Fundamentals of the Analytical Network Process: Dependence and Feedback in Decision-Making with a Single Network.

Saaty, T.L., 2001. Decision-Making with the AHP: Why is The Principal Eigenvector Necessary. ISAHP 2001, Berne, Switzerland, August 2-4, 2001.

Roberts, Edward B., 1988. Managing Invention and Innovation. Research and Technology Management 31 (1), 1-27.

\section{Appendices}

Example of questionaire

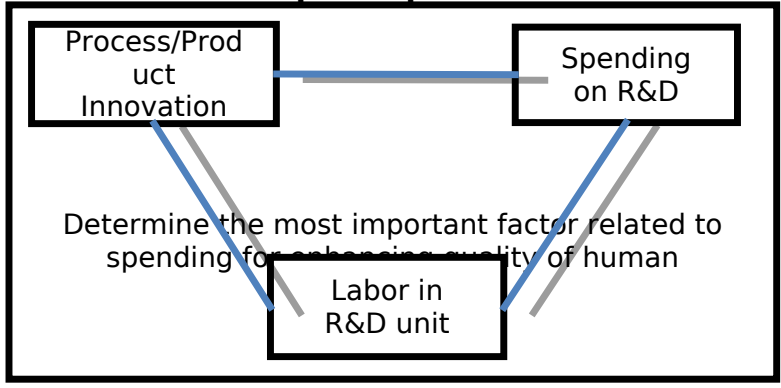

International Symposium of the Analytic Hierarchy

Process
Priority Matrix

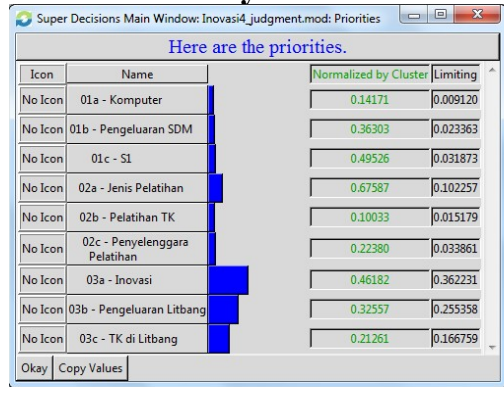

Washington, D. C. June 29 - July 2, 2014 
IJAHP Article: Mu, Saaty/A Style Guide for Paper Proposals To Be Submitted to the International Symposium of the Analytic Hierarchy Process 2014, Washington D.C., U.S.A. 